\title{
Suitability of the Lebanese "Ace Spur" Apple Variety for Cider Production Using Hanseniaspora sp. Yeast
}

\author{
Marina Al Daccache 1,2, Mohamed Koubaa ${ }^{3, * \mathbb{D}}$, Richard G. Maroun ${ }^{2} \mathbb{D}$, Dominique Salameh ${ }^{2}$, \\ Nicolas Louka ${ }^{2}$ and Eugène Vorobiev ${ }^{1}$ \\ 1 Sorbonne University, Université de Technologie de Compiègne, ESCOM, EA 4297 TIMR, Centre de \\ Recherche Royallieu, CS 60319, 60203 Compiègne, CEDEX, France; \\ marina.daccache@net.usj.edu.lb (M.A.D.); eugene.vorobiev@utc.fr (E.V.) \\ 2 Faculteé des Sciences, Centre d'Analyses et de Recherche, UR TVA, Laboratoire CTA, Universiteé \\ Saint-Joseph, Beyrouth 1104 2020, Lebanon; richard.maroun@usj.edu.lb (R.G.M.); \\ dominique.salameh@usj.edu.lb (D.S.); nicolas.louka@usj.edu.lb (N.L.) \\ 3 ESCOM, UTC, EA 4297 TIMR, 1 allée du réseau Jean-Marie Buckmaster, 60200 Compiègne, France \\ * Correspondence: m.koubaa@escom.fr; Tel.: +33-344238841
}

Received: 22 December 2019; Accepted: 4 March 2020; Published: 8 March 2020

\begin{abstract}
In the present research work, the physicochemical and fermentative properties of the "Ace spur" apple variety, obtained from a Lebanese farm, and the "Kermerrien" variety, obtained from a French cider industry, were investigated. The pomological properties were first determined for both varieties showing significant differences in the shapes and sizes. Sugar content, titratable acidity, soluble solids, and $\mathrm{pH}$ values were then determined. The potential of the "Ace spur" apple juice was then evaluated using the yeast strain Hanseniaspora sp., a major yeast found during the spontaneous fermentation of apples. "Ace spur" apples contained more sugars while the "Kermerrien" cultivar had a highest malic acid and polyphenol concentrations. After $100 \mathrm{~h}$ of fermentation, the ethanol percentage $(v / v)$ was around $4 \%$ in both ciders. Results obtained in this work revealed the chemical potential of the Lebanese apple juice to produce cider.
\end{abstract}

Keywords: Lebanese apple; fermentation; cider; Hanseniaspora sp.; physicochemical properties

\section{Introduction}

Apple represents one of the most produced and consumed fruits in the world. It is ranked as the third fruit produced worldwide with 77 million tons during the season of 2016-2017 [1]. It is a major fruit tree crop grown in the Mediterranean region [2]. "Ace Spur", a dessert apple variety, represents one of the most important cultivars grown in the world [3]. In Lebanon, apple production is one of the active fruit-growing sectors. Despite the fact that most of the apples produced are either sold in the local market or exported, many apples remain unsold. Thus, the processing and fermentation of the apples to produce beverages such as cider could be a promising perspective to exploit the potential of the unused apples. Nonetheless, the apple composition is one of the important factors to be considered as the aroma compounds usually define the quality of the fermented beverages. The content of these compounds could be affected by several factors including the apple variety, the fermentation conditions, and the yeast strain used [4-6]. Determining the physicochemical properties of apples before their use for fermentation processes is thus crucial to obtain a high product quality. Specific varieties of cider apples are grown and dedicated specifically for cider production. Based on their chemical composition, the different varieties of cider apples are divided into several categories. The "Kermerrien" variety is used during this study. The productivity of this variety is around 35-40 tons/ha in France. It is a bitter variety, characterized by a conical shape, and a green to red color. The flavor of the must deriving from is rather bittersweet and slightly fragrant, thus generating a bitter cider [7]. 
Apple sugar content could change depending on many factors such as the climatic factors including light, temperature, and moisture, as well as the cultivar and the maturity level of the fruit $[8,9]$. Mature apples are mainly composed of $\approx 85 \%$ water, $12 \%-14 \%$ carbohydrates, $0.3 \%-1.0 \%$ organic acids, $0.3 \%$ proteins, less than $0.1 \%$ lipids, as well as minerals and vitamins [10]. Fructose, glucose, and sucrose are the main sugars characterizing the fruit quality and the market value of apples [11,12]. Unlike other fruits, fructose content is significantly higher than that of glucose $[13,14]$. In a study of eight commercially growing apple varieties in China, the average contents of fructose, glucose, and sucrose were reported as $53.9 \mathrm{~g} / \mathrm{L}, 33.8 \mathrm{~g} / \mathrm{L}$, and $24 \mathrm{~g} / \mathrm{L}$, respectively [15]. Moreover, it was noted that the sensory characteristics of the product could be affected by the ratio of glucose and fructose. For instance, during the fermentation, the yeasts usually prefer to consume more glucose than fructose. Thus, a high fructose content in apple juice may affect the taste of the dry ciders after fermentation [16-18]. A total soluble solid content of $98.8 \%$ sugars represents a standard index of fruit ripening [19].

Soluble sugars and organic acids are important constituents contributing to the organoleptic properties of the fruits. They create with the flavoring substances the organoleptic quality related to the fresh apples [20]. L-malic acid is the major organic acid found in apples and its content closely correlates the titratable acidity. It is followed by the citric acid in a very lower concentration [21]. It has been also reported that apple fruit contains at least nine to twelve other organic acids in smaller fractions such as tartaric, quinic, shikimic, and succinic acids [15]. Apple acidity may vary from 0.1 to $2.5 \mathrm{~g}$ of malic acid per $100 \mathrm{~g}$ of juice [22]. The fruits growing in cool climate regions are usually more acidic than those growing in warmer regions [23].

The phenolic compounds' content has also an important effect on the sensory properties (e.g., color, bitterness, and astringency) of apple ciders. They could be involved in the fermentative process, providing the cider aroma, and as inhibitors of the microorganism growth [24]. In addition, they can influence the sweetness and the sourness, and therefore may affect the overall flavor development during the fermentation process $[25,26]$. Several types of phenolic compounds are found in apple cultivars, specifically, hydroxycinnamic acid derivatives, monomeric and oligomeric flavan-3-ols, dihydrochalcones, and flavonols [27]. Moreover, differences in the polyphenolic profile may occur between apple varieties and the final phenol content may depend on several factors such as the maturity of the fruit, the harvest year, climate conditions, cultivation, and storage conditions [24,27].

Other important parameters to take into account for apple processing are the fruit size and shape. They are essential for the equipment design for handling, transporting, cleaning, sorting, grading, and processing of the fruit [28].

Besides the chemical composition, the selection of yeast has a significant impact on fermentation. Different yeasts may be present during the first stage of fermentation, giving way to another type of yeast, now called Saccharomyces cerevisiae [29]. This yeast is widely used during fermentation due to its controlled and repetitive behavior as well as for the release of its aroma precursors. The role of non-Saccharomyces yeasts appears to be important during the fermentation process. These species are characterized by a low fermentation capacity and are sensitive to an alcohol concentration close to $5 \%-6 \%$ [30]. The positive impact of Hanseniaspora sp. in alcoholic fermentation has been demonstrated, which may positively contribute to the aroma profile of the fermented apple juice, thereby accentuating the beneficial role of these yeasts [31,32]. The species of the genus Hanseniospora are characterized by an apiculate form and are present at the beginning of spontaneous fermentation [33-37].

The review of the literature shows that the information about the physicochemical properties of the Lebanese apples and their potential to produce cider by fermentation is very limited. In this line, this study aimed to determine the physical properties and chemical composition of one Lebanese apple variety; "Ace spur", as well as its suitability for cider production. 


\section{Materials and Methods}

\subsection{Apples and Chemicals}

Two apple cultivars ("Ace spur" and "Kermerrien") were used in this study. The "Ace spur" apples were collected from Bqaatouta village (Keserwan region, Lebanon) and it was chosen due to its high availability in the Lebanese market. Previous studies have shown the great potential of this variety for cider production [38,39]. The "Kermerrien" variety was kindly provided by the IFPC ("Institut Français des Productions Cidricoles") located in "Le rheu" city (France). This variety is traditionally cultivated for industrial cider production. The apples were brought during the same harvest period (2017/2018 season) to minimize the errors due to the apple storage and ripening. They were stored at $4{ }^{\circ} \mathrm{C}$ until use.

Acetonitrile $\left(\mathrm{CH}_{3} \mathrm{CN}\right)$, ethanol $\left(\mathrm{C}_{2} \mathrm{H}_{5} \mathrm{OH}\right)$, and peptone were purchased from Fisher Scientific (Illkirch, France). Gallic acid, malic acid, Folin-Ciocalteu phenol reagent, Trolox, and yeast extract were purchased from Sigma-Aldrich (Saint-Quentin-Fallavier, France). Fructose, sucrose, and glucose were supplied by Merck Millipore (Guyancourt, France). Sodium carbonate was bought from Prolabo (Fontenay-sous-Bois, France).

\subsection{Determination of the Apple Properties}

\subsubsection{Determination of the Size and Shape Properties}

The experiments were performed in triplicate over 25 different apples taken from each variety. First, the fruit weight (g) was measured using a monobloc Mettler Toledo PB3002-S precision balance (Aldrich, Germany). After this step, the polar $(L)$, suture $(W)$, and equatorial $(T)$ diameters (Figure 1 ) of each apple were measured using a digital vernier caliper (Athol, MA, USA).

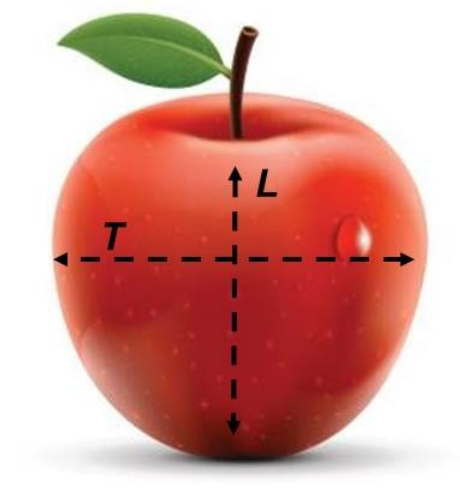

Polar (L) and equatorial (T) diameters

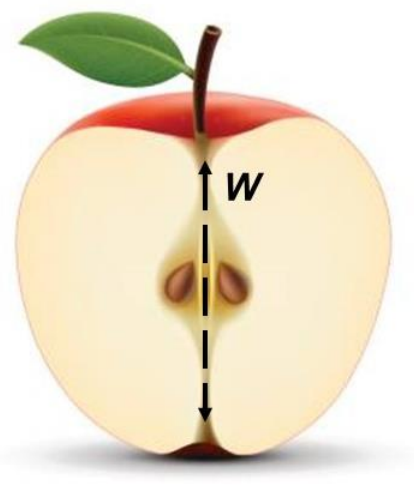

Suture (W) diameter

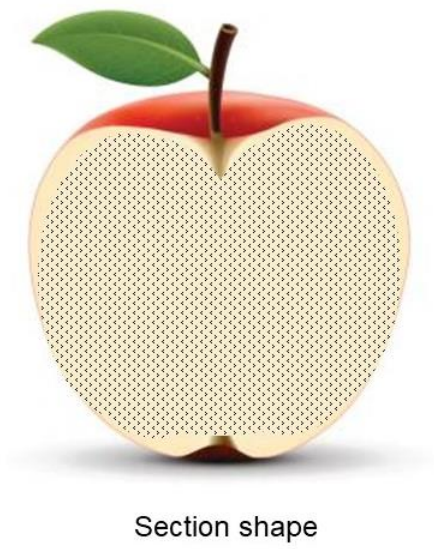

Section shape

Figure 1. Schematic representation of the apple size and shape determination.

The measurement of these three dimensions allowed the calculation of the following parameters [40,41]. The elongation $E$ (Equation (1)):

$$
E=\frac{T}{L}
$$

The "size" or the arithmetic mean diameter: $D a(\mathrm{~mm})$ (Equation (2)).

$$
D a(\mathrm{~mm})=\frac{T+L+W}{3}
$$

The geometric mean diameter: $D g(\mathrm{~mm})$, and the equivalent diameter: $D e(\mathrm{~mm})$ were calculated using Equations (3) and (4) [42].

$$
D g(\mathrm{~mm})=\sqrt[3]{L \cdot W \cdot T}
$$




$$
D e(\mathrm{~mm})=\left(\frac{L \cdot(W+T)^{2}}{4}\right)^{\frac{1}{3}}
$$

The surface area: $S\left(\mathrm{~mm}^{2}\right)$ was calculated from Equation (5)

$$
S\left(\mathrm{~mm}^{2}\right)=\pi \cdot T \cdot\left(L+\frac{T}{2}\right)
$$

The fruit volume: $V\left(\mathrm{~mm}^{3}\right)$ was calculated according to Equation (6) [43]:

$$
V\left(\mathrm{~mm}^{3}\right)=\frac{\pi \cdot L \cdot W \cdot T}{6}
$$

\subsubsection{Mechanical Analyses}

Relaxation Test

Relaxation tests were conducted at room temperature in order to quantify and qualify the viscous phenomena and the resistance within the products [44]. The tests were carried out using a texture analyzer (TA-XT plus, Rhéo, Champlan, France) consisting of a force sensor, a pressing piston, and a computer that allows the acquisition, the recording of measurements, and the data processing. The samples were prepared in the sliced form of $1.7 \mathrm{~cm}$ diameter and $1 \mathrm{~cm}$ thickness using a cylindrical punch tool. A force of $10 \mathrm{~N}$ and a displacement speed of $1 \mathrm{~mm} / \mathrm{s}$ with a maximum deformation of $10 \%(1 \mathrm{~mm})$ were applied.

\section{Cutting/Slicing Test}

The goal of this test is to compare the force required for cutting or slicing a product. The device used was the same texturometer described above (TA-XT plus, Rhéo, Champlan, France), equipped with a sharp blade. During this test, a movement speed of $1 \mathrm{~mm} / \mathrm{s}$ was imposed (Figure 2). The samples were prepared in the sliced form of $1.7 \mathrm{~cm}$ diameter and $1 \mathrm{~cm}$ thickness. The strength necessary to cut the product to $50 \%$ of its initial thickness was delivered.

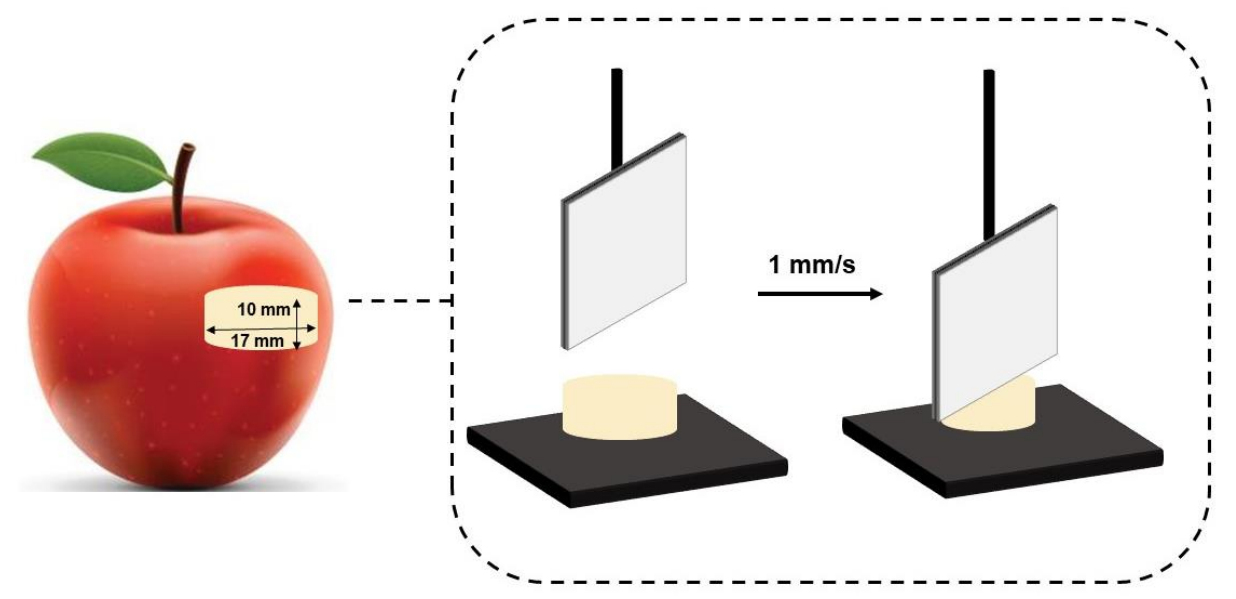

Figure 2. Schematic representation of the cutting test procedure.

\subsubsection{Determination of the Water Content in Apples}

The apples were cut into small cubes $(\approx 2 \mathrm{~cm})$ from different fruit parts (pulp, center cut, pulp, and skin). The water content in apple slices was determined using an infrared dryer (Sartorius MA150, Aubagne, France). The principle consists of heating the sample at $105^{\circ} \mathrm{C}$ until obtaining a constant weight. The test was performed in triplicate for each variety. 


\subsection{Determination of the Biochemical Properties}

Randomly $5 \mathrm{~kg}$ of apples were chosen from $\approx 300 \mathrm{~kg}$. The apples were first washed and then used to extract the juices at room temperature using a fruit juice centrifuge separator (Moulinex, France). The biochemical properties, detailed in the following sections, were determined immediately after juice extraction. All measurements were repeated at least using three replicates.

\subsubsection{Titratable Acidity}

The titratable acidity represents the total acid content in apple juice and was expressed as malic acid equivalent. The titratable acidity was calculated as the average of 5 measurements (each of $100 \mathrm{~mL}$ diluted juice) with a $0.1 \mathrm{~N} \mathrm{NaOH}$ solution.

\subsection{2. $\mathrm{pH}$ Measurement}

The $\mathrm{pH}$ of the juice was determined with a Mettler Toledo (MP 220) $\mathrm{pH}$ meter.

\subsubsection{Total Soluble Solids (Brix \% $(\mathrm{s}, \mathrm{w})$ )}

Aliquots of both juices were taken to measure the total soluble solids using a digital refractometer (Thermo Scientific, Illkirch, France) [45].

\subsubsection{Analysis of the Total Polyphenol Content}

The total polyphenol content was determined for both apple juice varieties. The Folin-Ciocalteu colorimetric method was used [46]. First, $1 \mathrm{~mL}$ of 10-fold diluted Folin-Ciocalteu reagent was added to $0.2 \mathrm{~mL}$ of the juice. Then, $0.8 \mathrm{~mL}$ of sodium carbonate $\left(\mathrm{Na}_{2} \mathrm{CO}_{3}\right)(75 \mathrm{~g} / \mathrm{L})$ solution was added and the mixture was incubated at $60^{\circ} \mathrm{C}$ for $10 \mathrm{~min}$. After cooling to room temperature, the absorbance was measured at $750 \mathrm{~nm}$ using a UV-vis spectrophotometer (Thermo Spectronic Genesys 20, Thermo Electron Corporation, Waltham, MA, USA). A calibration curve was established using gallic acid solutions (concentrations ranging from 0.2 to $1 \mathrm{mg} / \mathrm{mL}$ ), and the polyphenols' content was expressed as $\mathrm{mg}$ of gallic acid equivalent per $100 \mathrm{~g}$ of dry matter.

\subsubsection{Determination of the Free Radical Scavenging Activities}

The DPPH (1,1-diphenyl-2-picrylhydrazyl) radical was used to determine the free radical scavenging activity of each apple juice variety [47]. A juice sample of $50 \mu \mathrm{L}$ was mixed with $1450 \mu \mathrm{L}$ of $0.06 \mathrm{mM} \mathrm{DPPH}$ free radical prepared in methanol solution. After $30 \mathrm{~min}$ incubation at room temperature, the reduction of the DPPH free radical was measured by reading the absorbance at $517 \mathrm{~nm}$. The DPPH free radical scavenging activity was measured using a spectrophotometer UV-vis (Libra S32, Biochrom, France). Trolox, as a synthetic antioxidant, was used as a positive control and the percentage of inhibition was calculated according to Equation (7).

$$
\text { Inhibition }(\%)=\frac{\text { Absorbance of control }- \text { Absorbance of test sample }}{\text { Absorbance of control }}
$$

\subsection{Determination of the Fermentative Capacity}

The evolution of the fermentative capacity of the Lebanese apple juice ("Ace Spur" variety) was performed using the yeast strain Hanseniaspora sp. This strain belongs to the authors' laboratory collection (Saint Joseph University, Beirut, Lebanon) [48]. This indigenous yeast strain was previously isolated from a spontaneously fermented juice of the Lebanese apple variety "Ace spur". In fact, the genus Hanseniaspora was found as a major yeast developed during spontaneous apple juice fermentation $[49,50]$. The sequencing of the internal transcribed spacer (ITS) domain of ribosomal DNA (SUB6436410 Hsp_E2MN648725) identified the isolated yeast strain as a member of the Hanseniaspora genus. First, a pre-culture was performed by taking one colony of the strain from YPD agar (1\% yeast 
extract, $2 \%$ peptone, $2 \%$ dextrose, and $2 \%$ agar) plate into $250 \mathrm{~mL}$ of liquid YPD (1\% yeast extract, $2 \%$ peptone, $2 \%$ dextrose) medium at $\mathrm{pH} 3.5$ under sterile conditions $\left(20 \mathrm{~min}\right.$ at $121{ }^{\circ} \mathrm{C}$ in an autoclave HMC HV-110L (HMC Europe GmbH, Tüssling, Germany)). The cultivation was performed during $24 \mathrm{~h}$ at $30{ }^{\circ} \mathrm{C}$ temperature, and $250 \mathrm{rpm}$ agitation speed in a thermostatic shaker (Thermo Scientific, Illkirch, France). A volume of $1.5 \mathrm{~L}$ of apple juice was introduced into a $2 \mathrm{~L}$ sterile fermenter and inoculated by the pre-culture to get an initial concentration of $3.0 \times 10^{6}$ cells $/ \mathrm{mL}$. The cultivation was performed in triplicate at $30{ }^{\circ} \mathrm{C}$ and $250 \mathrm{rpm}$. Samples were periodically taken during the fermentation process for yeast cell counting. Several dilutions were made in ultrapure water, and the cells were counted using a Thoma cell counting chamber (Preciss, France). The biomass concentration X (cells/mL) was calculated according to Equation (8), where $n$ is the number of cells counted, $d$ is the dilution factor, $N$ is the number of squares counted in the chamber, and 250,000 corresponds to a constant included in the formula of the Thoma cell. To detect the viable cells, the samples were mixed volume to volume with a solution of $0.01 \%$ methylene blue.

$$
X(\text { cells } / \mathrm{mL})=\frac{n \cdot 250,000 \cdot d}{N}
$$

The ethanol production during the fermentation process was determined by the specific gravity measurements using a $5 \mathrm{~mL}$ glass pycnometer (Thermo Fisher, Illkirch, France). For ethanol quantification, a calibration curve was prepared using reconstituted solutions of apple juice/ethanol (1-10\%, v/v).

The concentrations of carbon substrates (fructose, glucose, and sucrose) were determined using high-performance liquid chromatography instrument LC-20AD (Shimadzu, Japan). The separation was performed in isocratic mode (a mixture of 1:4 (20:80) (v:v) water:acetonitrile with a flow rate of $3 \mathrm{~mL} / \mathrm{min}$ ), and using a Luna $5 \mu \mathrm{m} \mathrm{NH}_{2} 250 \times 4.6 \mathrm{~mm}$ column. The separation temperature was set to $40{ }^{\circ} \mathrm{C}$ and the eluted molecules were detected using a low-temperature evaporative light scattering detector ELSD-LT II (Shimadzu, Japan). The samples taken during the fermentation processes were diluted 10 times in ultrapure water, and a volume of $1 \mu \mathrm{L}$ was injected. The compounds' assignation and quantification were performed using pre-established standard curves of glucose (5-30 g/L), fructose $(2.5-30 \mathrm{~g} / \mathrm{L})$, and sucrose $(2-10 \mathrm{~g} / \mathrm{L})$. The kinetics of growth, ethanol production, and substrate consumption were compared to those obtained for the fermented "Kermerrien" juice, performed under the same conditions.

\subsection{Statistical Analysis}

One-way analysis of variance (ANOVA) was used for the statistical analysis of the data using Statgraphics Plus software (version 5.1, Statpoint Technologies Inc., Warrenton, VA, USA). Significance level at 95\% confidence was taken for each analysis. The values presented in the figures correspond to the mean value of the repetition, and the error bars correspond to the standard deviations of each measurement.

\section{Results and Discussion}

\subsection{Apple Pomological Properties}

The choice of variety and the knowledge of the cultivar composition allow establishing the sensory quality of the apple juice. The data presented in Table 1 show significant differences in the fruits' properties. The "Ace spur" variety seems to have a bigger size (56.72 $\pm 3.44 \mathrm{~mm}$ vs. $44.10 \pm 1.83 \mathrm{~mm})$, volume $\left(174.1 \pm 4.8 \mathrm{~cm}^{3}\right.$ vs. $\left.49.22 \pm 8.2 \mathrm{~cm}^{3}\right)$, and weight $(117.13 \pm 20.01 \mathrm{~g}$ vs. $60.57 \pm 8.34 \mathrm{~g})$ compared to that of the "Kermerrien" apple. Furthermore, the shapes are significantly different between the two varieties: a circular section shape for the "Ace spur" variety $(E \approx 1)$, and ovoid for the "Kermerrien" one $(E>1)$ (Figure 3). In fact, it has been reported that the elongation might depend on the cultivar and the orientation of the fruit in the space [51]. In the current study, the two varieties of apples chosen came from two different regions. The "Ace spur" variety is mainly dedicated to daily consumption 
where the appearance of the apple has an essential role, whereas the "Kermerrien" variety is a cider apple cultivated to produce cider and is not consumed as a dessert apple. Figure 3 shows that the "Ace spur" variety has a more attractive appearance, which is important for commercial reasons, while "Kermerrien" apples are grown exclusively for processing. Those apples have some imperfections, such as skin blemishes or off shapes (Figure 3), making them undesirable for the fresh market. The fruit size and shape could also be a tool to distinguish the fruits from each other. These properties can also be exploited to determine the parameters for postharvest, sorting, and processing. It should be also integrated in the design of equipment.

Table 1. Average fruit weight, linear dimensions, size, elongation, and rheological properties of 25 apples taken from "Ace spur" and "Kermerrien" vartieties.

\begin{tabular}{|c|c|c|}
\hline Apple Variety & "Ace Spur" & "Kermerrien" \\
\hline Average weight $(\mathrm{g})$ * & $117.13 \pm 20.01$ & $60.57 \pm 8.34$ \\
\hline Equivalent mean diameter $D e(\mathrm{~mm})$ * & $56.72 \pm 3.44$ & $44.10 \pm 1.83$ \\
\hline Mean size $D a(\mathrm{~mm}) *$ & $56.76 \pm 3.34$ & $44.12 \pm 1.62$ \\
\hline Mean elongation $E$ & $1.05 \pm 0.07$ & $1.14 \pm 0.2$ \\
\hline Mean Surface area $S\left(\mathrm{~cm}^{2}\right)$ & $180.14 \pm 5.4$ & $119.17 \pm 3.7$ \\
\hline Mean fruit volume $V\left(\mathrm{~cm}^{3}\right) *$ & $174.1 \pm 4.8$ & $49.22 \pm 8.2$ \\
\hline Water content $(\%)$ & $82.34 \pm 2.1$ & $84.15 \pm 1.5$ \\
\hline Compression force $(\mathrm{N}) *$ & $64.88 \pm 15.7$ & $118.37 \pm 20.5$ \\
\hline Rupture force $(\mathrm{N})$ & $14.85 \pm 1.87$ & $14.57 \pm 2.5$ \\
\hline
\end{tabular}

The * denotes significant differences.

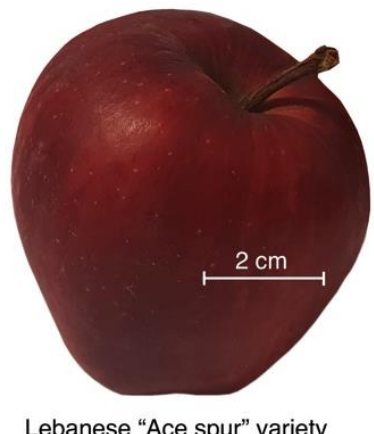

Lebanese "Ace spur" variety

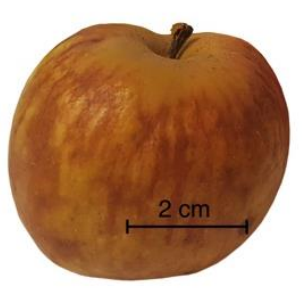

French "Kermerrien" variety

Figure 3. Morphological aspects of the Lebanese "Ace spur" and the French "Kermerrien" apple varieties.

Extracting and milling the apples for apple juice recovery are essential operations during the first steps of the cider production process [52]. Apple pressing and crushing require a certain force, thus the design of the machines and presses will be manufactured according to this force to obtain an optimum yield of juice. The needed force to rupture the "Ace spur" apples was lower than that of the "Kermerrien" one (Table 1). This indicates that the Lebanese variety has a softer tissue compared to that of the French one. Nonetheless, the force required to cut the apples was the same for both varieties. Furthermore, the results in Table 1 show that the "Ace spur" apples had slightly lower water content than the "Kermerrien" apples $(82.34 \% \pm 2.1 \%$ vs. $84.15 \% \pm 1.5 \%)$. Water content is related to the texture and apple firmness. It may depend on the total soluble solids present in each variety. The lowest water content observed in the "Ace spur" apples concurs with the high total soluble solids $(20.57 \pm 1.80 \mathrm{~g} / 100 \mathrm{~mL})$ found (Table 2). 
Table 2. Physicochemical apple juice composition of "Ace spur" and "Kermerrien" varieties.

\begin{tabular}{ccc}
\hline Apple Variety & "Ace Spur" & "Kermerrien" \\
\hline Glucose $(\mathrm{g} / \mathrm{L}){ }^{*}$ & $55.69 \pm 1.54$ & $39.80 \pm 1.60$ \\
Fructose $(\mathrm{g} / \mathrm{L}){ }^{*}$ & $101.41 \pm 4.08$ & $57.84 \pm 1.98$ \\
Sucrose $(\mathrm{g} / \mathrm{L})$ & $35.98 \pm 1.89$ & $34.59 \pm 1.23$ \\
Total sugar content $(\mathrm{g} / \mathrm{L}){ }^{*}$ & $193.08 \pm 7.51$ & $132.32 \pm 4.81$ \\
Fructose-Glucose ratio * & $1.83 \pm 0.08$ & $1.45 \pm 0.05$ \\
${ }^{\circ}$ Brix $(\mathrm{g} / 100 \mathrm{~mL}){ }^{*}$ & $20.57 \pm 1.80$ & $13.57 \pm 0.80$ \\
Titratable acidity (g malic acid/L) * & $2.93 \pm 0.66$ & $15.28 \pm 1.90$ \\
Ph * & $4.90 \pm 0.08$ & $3.59 \pm 0.09$ \\
Total phenolic content (mg GAE/100 g dry matter) * & $419.83 \pm 8.32$ & $514.13 \pm 13.75$ \\
Total antioxidant activity $(\%){ }^{*}$ & $93.15 \pm 0.87$ & $95.97 \pm 0.5$ \\
\hline
\end{tabular}

The * denotes significant differences, GAE denotes Gallic Acid Equivalent.

\subsection{Apples Composition}

The most abundant sugars in apples are fructose and glucose [4]. They represent $81 \%$ of the total sugars in the "Ace spur" and 74\% in the "Kermerrien" variety. The results obtained (Table 2) showed that the concentrations of glucose and fructose in the two varieties are significantly different. Even more, the fructose/glucose ratio was greater for the "Ace spur" variety $(1.83 \pm 0.08)$ than that of the "Kermerrien" one $(1.45 \pm 0.05)$. Furthermore, the results showed a strong positive correlation between the total sugar content and the total soluble content $\left({ }^{\circ}\right.$ Brix), though the sucrose concentration was the same for both varieties (Table 2). The fructose concentration in the "Ace spur" variety was relatively high compared to the values found in the literature. The "Kermerrien" variety is considered as a bitter apple cider having a relatively low sugar concentration. In fact, different fructose concentrations were found in the literature. In a study of eight apple varieties obtained from the Polish market, a range of fructose concentration between 82.2 and $59.3 \mathrm{~g} / \mathrm{L}$, and an average of $23.15 \mathrm{~g} / \mathrm{L}$ of glucose concentration were reported [53]. In the Latvian apples, the fructose content ranged from 23.5 to $66.91 \mathrm{~g} / \mathrm{L}$, while the glucose concentration ranged from 7.47 and $60.24 \mathrm{~g} / \mathrm{L}$ [54]. Several authors have investigated the relationship between apple sweetness and its properties. For example, a relationship is demonstrated between apple sweetness and texture properties [55] or apple color [56]. A great difference in the textures and colors of the two varieties is discussed above and shown in Table 1 and Figure 3. The texture differences may justify the significant differences in the sugar concentrations between the "Ace spur" and "Kermerrien" apples.

However for cider production, usually apple cider varieties contain $11 \%$ of glucose, $74 \%$ of fructose, and $15 \%$ of sucrose [4]. Lea and Drilleau, described the "ideal" composition of apple juice for cider production and categorized the apple cider varieties into four groups depending on the concentration of sugars, organic acids, and phenolic compounds [8]. The "Ace spur" variety containing high sugar concentrations should be belonging to the "sweet" apple varieties. Furthermore, the comparison of the sugar content in the "Ace spur" variety to that of the "ideal" apple juice showed that the fructose and sucrose concentrations matched [8]. The glucose concentration was higher in the "Ace spur" variety with a slightly lower acid concentration, which means that the cider from the "Ace spur" variety could be sweeter than the cider from the "Kermerrien" apples. Yet, if an ideal composition is sought for the production of cider, different varieties of apples should be used.

Furthermore, a significant difference was observed between the total phenolic compounds of the two varieties (419.83 \pm 8.32 and $514.13 \pm 13.75 \mathrm{mg}$ GAE/100 g dry matter, for "Ace spur" and "Kermerrien" varieties, respectively) (Table 2). This could be related to the fact that the "Kermerrien" variety is specifically used for cider production, which should normally be rich in phenolic compounds [57,58]. Thus, for a good cider quality, it is important to note that the "Ace spur" apples should contain a relatively high phenolic compounds' content, which was comparable to that found in the "Kermerrien" variety. In fact, the color, 
astringency, bitterness balance, and other sensory properties (e.g., aroma and fruitiness) of cider depend on the concentration of phenolic compounds [54].

The antioxidant activity was slightly higher for the "Kermerrien" variety $(95.97 \% \pm 0.5 \%)$ compared to "Ace spur" (93.15\% $\pm 0.87 \%$ ) (Table 2). This could be correlated to the phenolic compounds content, as previously demonstrated [59]. In addition, even though the TPC is lower for the "Ace spur" variety, the polyphenolic compounds present similar antioxidant activity than that of apple cider (Table 2). In another study, it has been reported that a blended cider was ranking higher for acidity and flavor compared to a single cultivar (doesn't contain the ideal characteristics for a fermented cider). A blend containing both dessert and specific cider cultivars ranked highest for sweetness, appearance, and flavor [60].

\subsection{Fermentative Potential of the Lebanese Apple Juice}

The fermentative capacity of the Lebanese "Ace spur" apple juice was evaluated using Hanseniaspora sp. yeast strain and compared to that obtained from "Kermerrien" variety. The kinetics of growth, ethanol production, and substrate consumption were recorded during the fermentation (Figures 4 and 5).

The results in Figure 4A show that Hansenisapora sp. can grow in the apple juice with distinguishable latency, exponential and stationary phases. The evolution of the biomass concentration over time indicates that the yeast growth takes place following a typical fermentative kinetic. The concentration of microorganisms reached a maximum of $5 \times 10^{7}$ cells $/ \mathrm{mL}$ and $3.8 \times 10^{7}$ cell $/ \mathrm{mL}$ for the "Ace spur" and the "Kermerrien" fermentations, respectively. In Figure 4B, the maximum ethanol percentage of $\approx 3.8 \%(v / v)$ reached after $100 \mathrm{~h}$ of the "Ace spur" juice fermentation was not significantly different from that of the "Kermerrien" variety $(\approx 3.5 \%)$. In fact, the final ethanol content in French ciders is usually less than $4 \%$, fixed either by the regulation or by the consumers' preferences $[61,62]$. This content is variable from a country to another. In fact, different samples taken from Scotland's cider varieties were tested and the alcoholic strengths varied in a range of $4.1 \%$ to $7.4 \%$ volume [63]. Therefore, the ethanol percentage obtained in this work for the "Ace spur" variety seems to be acceptable for cider production.

A.

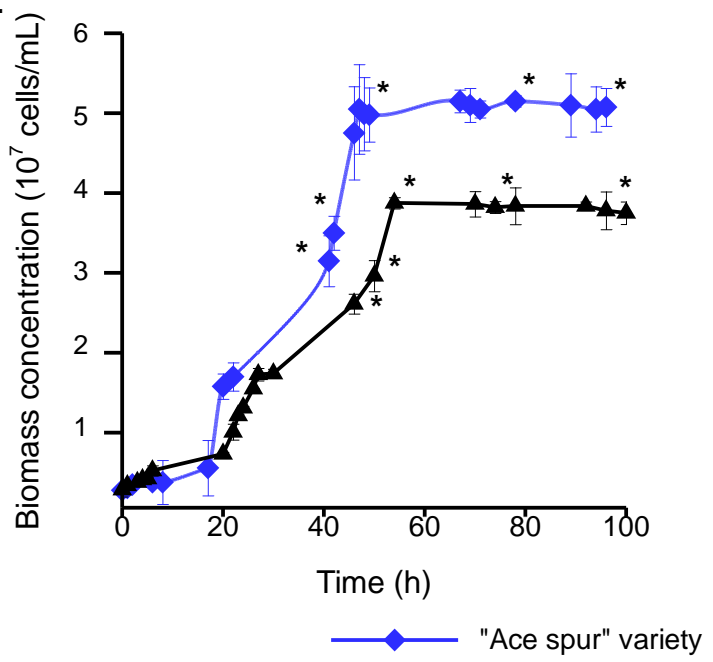

B.

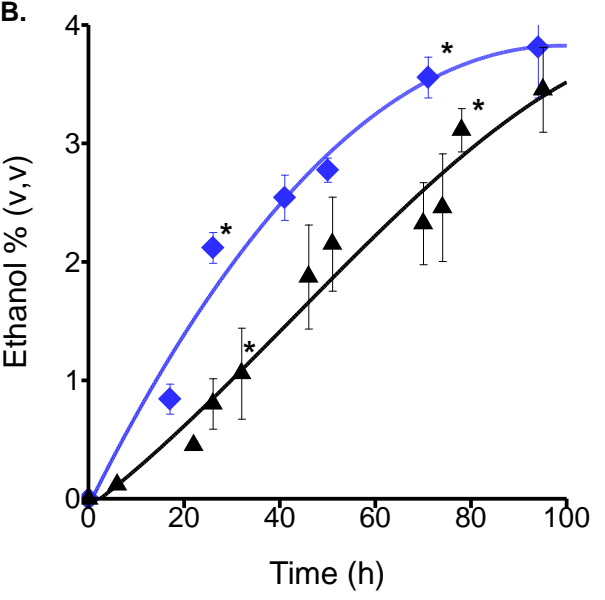

"Kermerrien" variety

Figure 4. Kinetics of growth (A) and ethanol production (B) of Hanseniaspora sp. fermentation in "Ace Spur" and "Kermerrien" apple juices. Continuous lines are provided to guide the eye. "** denotes significant differences.

During the Lebanese "Ace spur" fermentation, the yeast consumed $61.5 \mathrm{~g} / \mathrm{L}$ of the total sugar content after $100 \mathrm{~h}$ of fermentation, divided as follows: $38 \mathrm{~g} / \mathrm{L}$ (36.5\%) of fructose, $14.5 \mathrm{~g} / \mathrm{L}(26.51 \%)$ of glucose, and $9 \mathrm{~g} / \mathrm{L}(23.35 \%)$ of sucrose. For the fermentation of the "Kermerrien" apple juice, the yeast consumed $26.8 \mathrm{~g} / \mathrm{L}(53.28 \%)$ of fructose, $5.5 \mathrm{~g} / \mathrm{L}(13.96 \%)$ of glucose and $5.7 \mathrm{~g} / \mathrm{L}(20.11 \%)$ of sucrose, thus $38 \mathrm{~g} / \mathrm{L}$ of 
the total sugar in the juice was consumed after $100 \mathrm{~h}$ of fermentation (Figure 4 ). The yeast consumed therefore more sugars during the "Ace spur" juice fermentation. Fructose was the most consumed sugar in both fermentations followed by glucose. The fructose-glucose consumption ratio was 2.62 and 4.87 for the "Ace spur" and "Kermerrien" fermentations, respectively. Thus, the indigenous yeast seems to have a fructophilic character. This behavior was observed for the strain Hanseniaspora uvarum that didn't show any preference for glucose consumption [64].

A.

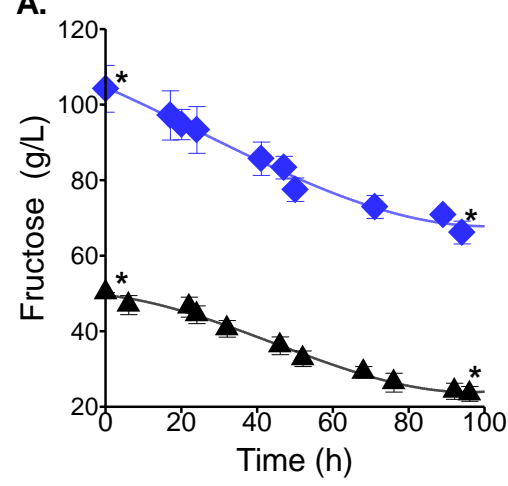

B.

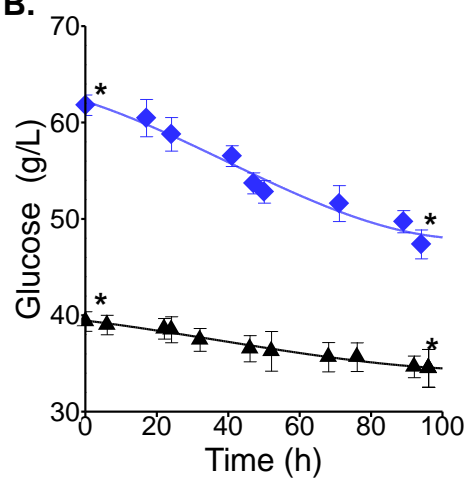

c.

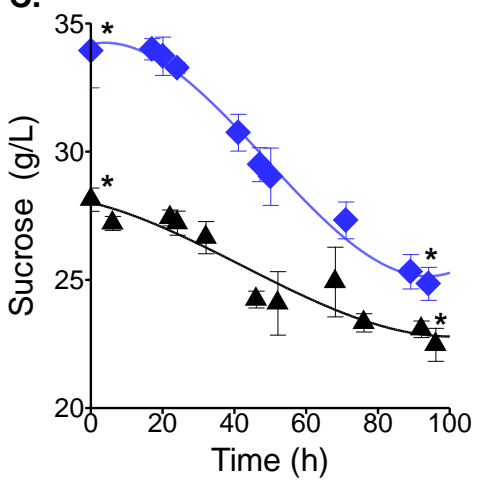

"Ace spur" variety

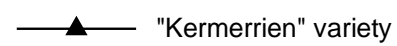

Figure 5. Evolution of the fermentative sugars (fructose (A), glucose (B), sucrose (C)) during the fermentation of the juice obtained from the "Ace Spur" and "Kermerrien" varieties. "**" denotes significant differences between the initial concentrations of the juice and after $100 \mathrm{~h}$ of fermentation.

The follow-up of the different fermentative kinetics (Figures 4 and 5) shows that regardless of the initial sugar concentration, the same ethanol percentage is reached in both fermentations after $100 \mathrm{~h}$. A closer look shows that different biomass and ethanol kinetics were obtained. The differences could be due to the significant variations observed in the initial sugar concentrations present in the two juices. In the presence of an excess of sugar, which is the case during the fermentation in the "Ace spur" juice, the yeast cells followed the fermentative pathway from the first hour of fermentation, generating both biomass and ethanol [65] (Figure 4). Nevertheless, for the fermentation of "Kermerrien" apple juice, where the concentration of sugars is practically by half $(\approx 110 \mathrm{~g} / \mathrm{L})$, the cells were in a respiratory mode generating biomass in the early hours of fermentation. The formation of ethanol seems to increase with the exhaustion of oxygen after hours of fermentation, thus the shift to the anaerobic fermentation mode may occur (Figure 4). Furthermore, the total sugar consumptions were strongly different. The yeast cells used the sugar less efficiently during the "Ace spur" fermentation, which produces a reduced amount of energy by following the fermentative pathway [65]. Thus, the yeast consumed more total sugars during this fermentation (Figure 4). Despite this higher consumption of sugars, the "Ace spur" cider may contain more total sugars, making it sweeter than the "Kermerrien" one.

\section{Conclusions}

In conclusion, the obtained results showed that the apple varieties "Ace spur" and "Kermerrien" had different pomological properties and chemical compositions. The "Ace spur" variety, a dessert apple, had a bigger size and a circular shape, while the "Kermerrien" variety cider apple had an ovoid shape with some imperfections. The "Ace spur" apples have a high sugar concentration, specifically a high fructose concentration $(\approx 100 \mathrm{~g} / \mathrm{L})$. The "Kermerrien" apples contained on the other hand high polyphenolic compounds content (514.13 mg GAE/100 g dry matter). The yeast strain Hanseniaspora sp. was able to ferment the "Ace spur" apple juice up to $\approx 3.8 \%$ of ethanol after $100 \mathrm{~h}$ of fermentation, which was comparable to that of the "Kermerrien" variety. The same ethanol content was reached regardless of the initial sugar concentration and the quantity of sugars consumed during both fermentations. The Lebanese "Ace spur" apple variety has the potential to be used for cider production due to its 
suitable chemical composition, it's appropriate texture for industrial processing, and the suitable ethanol content obtained after $100 \mathrm{~h}$ of fermentation. Nonetheless, further investigations are required to evaluate the volatile organic compounds and the aromatic profile of the obtained ciders.

Author Contributions: Conceptualization, M.K. and E.V.; methodology, M.A.D.; formal analysis, R.G.M. and D.S.; writing-original draft preparation, M.K. and M.A.D.; writing—review and editing, E.V., N.L., D.S. and R.G.M.; funding acquisition, E.V. and N.L. All authors have read and agreed to the published version of the manuscript.

Funding: This research was funded by the Research council of Saint-Joseph University of Beirut, grant number FS103 and by the Lebanese National Council for Scientific research, grant number CNRS-FS129.

Acknowledgments: The authors wish to thank the project funders as well as Nicolas Thiebault for his help in performing the HPLC analyses at ESCOM-Chimie (Compiègne, France).

Conflicts of Interest: The authors declare no conflict of interest.

\section{References}

1. United States Department of Agriculture. Fresh Deciduous Fruit: World Markets and Trade (Apples, Grapes $\mathcal{E}$ Pears); Foreign Agricultural Service: Washington, DC, USA, 2018.

2. Wilkie, J.D.; Sedgley, M.; Olesen, T. Regulation of floral initiation in horticultural trees. J. Exp. Bot. 2008, 59, 3215-3228. [CrossRef]

3. Al-Absi, K. Thinning intensity of 'Ace Spur Delicious' and "Idared" apples with ethephon, benzyladenine and their combination. Jordan J. Agric. Sci. 2009, 5, 237-250.

4. Beech, F.W. Cider making and cider research: A review. J. Inst. Brew. 1972, 78, 477-491. [CrossRef]

5. Hidalgo, P.; Pueyo, E.; Pozo-Bayón, M.A.; Martínez-Rodríguez, A.J.; Martín-Alvarez, P.; Polo, M.C. Sensory and analytical study of rose sparkling wines manufactured by second fermentation in the bottle. J. Agric. Food Chem. 2004, 52, 6640-6645. [CrossRef] [PubMed]

6. Martínez-Rodriguez, A.J.; Polo, M.C. Effect of the addition of bentonite to the tirage solution on the nitrogen composition and sensory quality of sparkling wines. Food Chem. 2003, 81, 383-388. [CrossRef]

7. Pomme à Cidre: Les Variétés, Institut Français des Productions Cidricoles; Sées, France, 2009.

8. Lea, A.G.H.; Drilleau, J.-F. Cidermaking. In Fermented Beverage Production; Lea, A.G.H., Piggott, J.R., Eds.; Springer US: Boston, MA, USA, 2003; pp. 59-87.

9. Kvåle, A. Composition and quality of gravenstein apples as related to some environmental factors. Acta Agric. Scand. 1969, 19, 229-239. [CrossRef]

10. Tablas Peruanas de Composición de Alimentos; Ministerio de Salud del Perú, Centro Nacional de Alimentación y Nutrición: Jesus María, Lima 11, Perú, 2009.

11. Knee, M. Pome fruits. In Biochemistry of Fruit Ripening; Seymour, G.B., Taylor, J.E., Tucker, G.A., Eds.; Chapman \& Hall: London, UK, 1993; pp. 325-346.

12. Baldwin, E.A. Fruit flavor, volatile metabolism and consumer perceptions. In Fruit Quality and its Biological Basis; Knee, M., Ed.; CRC Press LLC: Boca Raton, FL, USA, 2002; pp. 89-106.

13. Sánchez-Moreno, C.; Pascual-Teresa, S.D.; Ancos, B.D.; Cano, M.P. Nutritional values of fruits. In Handbook of Fruits and Fruit Processing; Hui, Y.H., Ed.; John Wiley \& Sons, Ltd.: Chichester, NH, USA, 2007; pp. $29-43$. ISBN 978-0-470-27773-7.

14. Sanz, M.L.; Villamiel, M.; Martínez-Castro, I. Inositols and carbohydrates in different fresh fruit juices. Food Chem. 2004, 87, 325-328. [CrossRef]

15. Wu, J.; Gao, H.; Zhao, L.; Liao, X.; Chen, F.; Wang, Z.; Hu, X. Chemical compositional characterization of some apple cultivars. Food Chem. 2007, 103, 88-93. [CrossRef]

16. Berthels, N.J.; Cordero Otero, R.R.; Bauer, F.F.; Thevelein, J.M.; Pretorius, I.S. Discrepancy in glucose and fructose utilisation during fermentation by Saccharomyces cerevisiae wine yeast strains. FEMS Yeast Res. 2004, 4, 683-689. [CrossRef]

17. Boulton, R.B.; Singleton, V.L.; Bisson, L.F.; Kunkee, R.E. Principles and Practices of Winemaking; Chapman \& Hall: New York, NY, USA, 1995; ISBN 978-1-4419-5190-8.

18. Fleet, G.H. Growth of yeasts during wine fermentations. J. Wine Res. 1990, 1, 211-223. [CrossRef] 
19. Riekstina-Dolge, R.; Kruma, Z.; Karklina, D.; Dimiňš, F. Physical-chemical parameters of Latvian apple juices and their suitability for cider production. Int. J. Nutr. Food Eng. 2014, 8, 263-267.

20. Nour, V.; Trandafir, I.; Ionica, M.E. Compositional Characteristics of Fruits of several Apple (Malus domestica Borkh) Cultivars. Not. Bot. Hort. Agrobot. Cluj 2010, 38, 228-233.

21. Campeanu, G.; Neata, G.; Darjanschi, G. Chemical composition of the fruits of several apple cultivars growth as biological crop. Not. Bot. Hort. Agrobot. Cluj 2009, 37, 161-164.

22. Valois, S.; Merwin, I.A.; Padilla-Zakour, O.I. Characterization of fermented cider apple cultivars grown in upstate New York. J. Am. Pomol. Soc. 2006, 60, 113-128.

23. Worobo, R.W.; Splittoesser, D.F. Microbiology of fruit products. In Processing Fruits; Barrett, D.M., Somogyi, L., Ramaswamy, H.S., Eds.; CRC Press: Boca Raton, FL, USA, 2004.

24. Nogueira, A.; Guyot, S.; Marnet, N.; Lequéré, J.M.; Drilleau, J.-F.; Wosiacki, G. Effect of alcoholic fermentation in the content of phenolic compounds in cider processing. Braz. Arch. Biol. Technol. 2008, 51, 1025-1032. [CrossRef]

25. Park, J. Characterizing and Improving the Oral Sensations and Preference of Polyphenol-Rich Aronia Berry Juice. Ph.D. Thesis, University of Connecticut, Storrs, CT, USA, 2014.

26. Symoneaux, R.; Baron, A.; Marnet, N.; Bauduin, R.; Chollet, S. Impact of apple procyanidins on sensory perception in model cider (part 1): Polymerisation degree and concentration. LWT Food Sci. Technol. 2014, 57, 22-27. [CrossRef]

27. Mangas, J.J.; Rodríguez, R.; Suárez, B.; Picinelli, A.; Dapena, E. Study of the phenolic profile of cider apple cultivars at maturity by multivariate techniques. J. Agric. Food Chem. 1999, 47, 4046-4052. [CrossRef]

28. Arshad, M.; Shahnawaz, M.; Shahkeela, S.; Hussain, M.; Ahmad, M.; Khan, S.S. Significance of physical properties of apple fruit influenced by preharvest orchard management factors. Eur. J. Exp. Biol. 2014, 4, 82-89.

29. Barnett, J.A. A history of research on yeasts 2: Louis Pasteur and his contemporaries, 1850-1880. Yeast 2000, 16, 755-771. [CrossRef]

30. Romano, P.; Suzzi, G.; Comi, G.; Zironi, R.; Maifreni, M. Glycerol and other fermentation products of apiculate wine yeasts. J. Appl. Microbiol. 1997, 82, 615-618. [CrossRef]

31. de Arruda Moura Pietrowski, G.; dos Santos, C.M.E.; Sauer, E.; Wosiacki, G.; Nogueira, A. Influence of fermentation with Hanseniaspora sp. yeast on the volatile profile of fermented apple. J. Agric. Food Chem. 2012, 60, 9815-9821. [CrossRef] [PubMed]

32. Capozzi, V.; Berbegal, C.; Tufariello, M.; Grieco, F.; Spano, G.; Grieco, F. Impact of co-inoculation of Saccharomyces cerevisiae, Hanseniaspora uvarum and Oenococcus oeni autochthonous strains in controlled multi starter grape must fermentations. LWT 2019, 109, 241-249. [CrossRef]

33. Lleixà, J.; Martín, V.; Portillo, M.D.C.; Carrau, F.; Beltran, G.; Mas, A. Comparison of Fermentation and Wines Produced by Inoculation of Hanseniaspora vineae and Saccharomyces cerevisiae. Front. Microbiol. 2016, 7, 338. [CrossRef] [PubMed]

34. López, S.; Mateo, J.J.; Maicas, S. Screening of Hanseniaspora strains for the production of enzymes with potential interest for winemaking. Fermentation 2016, 2, 1.

35. Martin, V.; Valera, M.J.; Medina, K.; Boido, E.; Carrau, F. Oenological impact of the Hanseniaspora/Kloeckera yeast genus on wines-A review. Fermentation 2018, 4, 76. [CrossRef]

36. Pretorius, I.S. Tailoring wine yeast for the new millennium: Novel approaches to the ancient art of winemaking. Yeast 2000, 16, 675-729. [CrossRef]

37. Zohre, D.E.; Erten, H. The influence of Kloeckera apiculata and Candida pulcherrima yeasts on wine fermentation. Process Biochem. 2002, 38, 319-324. [CrossRef]

38. Al Daccache, M.; Koubaa, M.; Salameh, D.; Maroun, R.G.; Louka, N.; Vorobiev, E. Ultrasound-assisted fermentation for cider production from Lebanese apples. Ultrason. Sonochem. 2020, 63, 104952. [CrossRef]

39. Al Daccache, M.; Koubaa, M.; Salameh, D.; Vorobiev, E.; Maroun, R.G.; Louka, N. Control of the sugar/ethanol conversion rate during moderate pulsed electric field-assisted fermentation of a Hanseniaspora sp. strain to produce low-alcohol cider. Innov. Food Sci. Emerg. Technol. 2020, 59, 102258. [CrossRef] 
40. Firatlıgil-Durmuş, E.; Šárka, E.; Bubník, Z. Image vision technology for the characterisation of shape and geometrical properties of two varieties of lentil grown in turkey. Czech J. Food Sci. 2007, 26, 109-116. [CrossRef]

41. Miloševi, T.; Miloševi, N.; Gliši, I.; Gliši, I.S. Determination of size and shape properties of apricots using multivariate analysis. Acta Sci. Pol. 2014, 13, 77-90.

42. Mohsenin, N.N. Physical Properties of Plant and Animal Materials: Structure, Physical Characteristics, and Mechanical Properties; Gordon and Breach: New York, NY, USA, 1986.

43. Jain, R.K.; Bal, S. Properties of pearl millet. J. Agric. Eng. Res. 1997, 66, 85-91. [CrossRef]

44. Marquina, P.L.; Burgos, J.; Oria, R. Application of a compression-relaxation test for the characterization of burlat sweet cherry. J. Texture Stud. 2001, 32, 15-30. [CrossRef]

45. Magwaza, L.S.; Opara, U.L. Analytical methods for determination of sugars and sweetness of horticultural products-A review. Sci. Hortic. 2015, 184, 179-192. [CrossRef]

46. Koubaa, M.; Mhemdi, H.; Vorobiev, E. Seed oil polyphenols: Rapid and sensitive extraction method and high resolution-mass spectrometry identification. Anal. Biochem. 2015, 476, 91-93. [CrossRef] [PubMed]

47. Brand-Williams, W.; Cuvelier, M.E.; Berset, C. Use of a free radical method to evaluate antioxidant activity. LWT Food Sci. Technol. 1995, 28, 25-30. [CrossRef]

48. Al Daccache, M.; Salameh, D.; Maroun, R.; Louka, N. New Indigenous Yeast Strains "Hanseniaspora Meyeri-Libani" for the Elaboration of Cider. 12017/10-11265L, 4 October 2017.

49. Pando Bedriñana, R.; Querol Simón, A.; Suárez Valles, B. Genetic and phenotypic diversity of autochthonous cider yeasts in a cellar from Asturias. Food Microbiol. 2010, 27, 503-508. [CrossRef]

50. Valles, B.S.; Bedriñana, R.P.; Tascón, N.F.; Simón, A.Q.; Madrera, R.R. Yeast species associated with the spontaneous fermentation of cider. Food Microbiol. 2007, 24, 25-31. [CrossRef]

51. Ercisli, S.; Sayinci, B.; Kara, M.; Yildiz, C.; Ozturk, I. Determination of size and shape features of walnut (Juglans regia L.) cultivars using image processing. Sci. Hortic. 2012, 133, 47-55. [CrossRef]

52. Downes, J.W. Equipment for extraction and processing of soft and pome fruit juices. In Production and Packaging of Non-Carbonated Fruit Juices and Fruit Beverages; Ashurst, P.R., Ed.; Springer US: Boston, MA, USA, 1995; pp. 197-220.

53. Wlodarska, K.; Pawlak-Lemanska, K.; Gorecki, T.; Sikorska, E. Perception of apple juice: A comparison of physicochemical measurements, descriptive analysis and consumer responses. J. Food Qual. 2016, 39, 351-361. [CrossRef]

54. Riekstina-Dolge, R.; Kruma, Z.; Dimins, F.; Straumite, E.; Karklina, D. Phenolic composition and sensory properties of ciders produced from Latvian apples. Rural Sustain. Res. 2014, 31, 39-45. [CrossRef]

55. Harker, F.R.; Amos, R.L.; Echeverríaa, G.; Gunson, F.A. Influence of texture on taste: Insights gained during studies of hardness, juiciness, and sweetness of apple fruit. J. Food Sci. 2006, 71, S77-S82. [CrossRef]

56. Bayarri, S.; Calvo, C.; Costell, E.; Durán, L. Influence of color on perception of sweetness and fruit flavor of fruit drinks. Food Sci. Technol. Int. 2001, 7, 399-404. [CrossRef]

57. Sanoner, P.; Guyot, S.; Marnet, N.; Molle, D.; Drilleau, J.P. Polyphenol profiles of French cider apple varieties (Malus domestica sp.). J. Agric. Food Chem. 1999, 47, 4847-4853. [CrossRef] [PubMed]

58. Will, F.; Schulz, K.; Ludwig, M.; Otto, K.; Dietrich, H. The influence of enzymatic treatment of mash on the analytical composition of apple juice. Int. J. Food Sci. Technol. 2002, 37, 653-660. [CrossRef]

59. Gliszczynska-Swiglo, A.; Tyrakowska, B. Quality of commercial apple juices evaluated on the basis of the polyphenol content and the teac antioxidant activity. J. Food Sci. 2003, 68, 1844-1849. [CrossRef]

60. Bradshaw, T.L.; Kingsley-Richards, S.L.; Foster, J. Apple cultivar evaluations for cider making in Vermont, USA. Acta Hortic. 2018, 453-460. [CrossRef]

61. Jarvis, B. The product and its manufacture-Chemistry and microbiology of cidermaking. In Encyclopedia of Food Sciences and Nutrition; Caballero, B., Ed.; Academic Press: Oxford, MI, USA, 2003; pp. 1312-1318. ISBN 978-0-12-227055-0.

62. Merwin, I.A.; Valois, S.; Padilla-Zakour, O.I. Cider apples and cider-making techniques in Europe and North America. In Horticultural Reviews; Janick, J., Ed.; John Wiley \& Sons, Ltd.: Chichester, NH, USA, 2008; pp. 365-415. ISBN 978-0-470-38014-7.

63. Lachenmeier, D.W.; Gill, J.S.; Chick, J.; Rehm, J. The total margin of exposure of ethanol and acetaldehyde for heavy drinkers consuming cider or vodka. Food Chem. Toxicol. 2015, 83, 210-214. [CrossRef] 
64. Wei, J.; Zhang, Y.; Wang, Y.; Ju, H.; Niu, C.; Song, Z.; Yuan, Y.; Yue, T. Assessment of chemical composition and sensorial properties of ciders fermented with different non-Saccharomyces yeasts in pure and mixed fermentations. Int. J. Food Microbiol. 2020, 318, 108471. [CrossRef]

65. Thierie, J.; Penninckx, M. Crabtree effect. In Encyclopedia of Industrial Biotechnology; Flickinger, M.C., Ed.; Wiley \& Sons, Ltd.: Chichester, NH, USA, 2010; pp. 1-18. ISBN 978-0-470-05458-1.

(C) 2020 by the authors. Licensee MDPI, Basel, Switzerland. This article is an open access article distributed under the terms and conditions of the Creative Commons Attribution (CC BY) license (http://creativecommons.org/licenses/by/4.0/). 